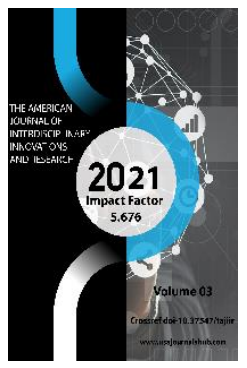

Journal Website: https://theamericanjou rnals.com/index.php/ta jiir

Copyright: Original content from this work may be used under the terms of the creative commons attributes 4.0 licence.

\section{The Determination Of Soil Moisturization Dynamics Four Factor Experience}

\author{
Sarimsakov Maksudkhon Musinovich \\ Candidate Of Agricultural Sciences, Researcher, Associate Professor, Fergana Polytechnic \\ Institute, Fergana, Uzbekistan \\ Kimsanov Ibrahim Khaitmuratovich \\ Candidate Of Agricultural Sciences, Associate Professor, Fergana Polytechnic Institute, \\ Fergana, Uzbekistan
}

\title{
ABSTRACT
}

This article presents the data of a four-factor experiment to determine the soil moisture perimeter in the field of drip irrigation in intensive gardening and to further increase the efficiency of water use.

\section{KEYWORDS}

Drip Irrigation System, Soil Moisture Perimeter, Soil Cultivation Depth, Irrigation Duration, Soil Bulk Density, Four-Factor Experiment.

\section{INTRODUCTION}

One of the most important issues today is the development of irrigated agriculture, increasing the efficiency of the use of land and water resources, enriching the domestic market with cheap and high-quality food, increasing the export potential, which is the main means of meeting people's demand for agricultural products.

The role of irrigated agriculture in ensuring the well-being of the economy and the standard of living of the country is invaluable. Irrigated lands are the main natural resource of the country. Therefore, the development of irrigated agriculture requires, first of all, the introduction of advanced technologies, an increase in the productivity of each hectare of irrigated land, and the efficient use of natural resources.

Today, intensive horticulture is an industry that meets the needs of several ten million people of the population in fruit products, and also increases the export potential of Uzbekistan. 
With the development of intensive horticulture, the rational use of land and water resources, soil and climatic conditions, the type of tree grown, and its biological properties are of great importance.

\section{RESEARCH METHODS}

In our study, we used a four-factor experience in determining soil moisture perimeters during irrigation using drip irrigation technology in intensive apple orchards. The advantage of this experiment is that, with the efficient use of water resources, it is important to determine the optimal depth of soil moisture. The four factors are tillage depth, dripper water consumption, irrigation time, and bulk density of the soil. Changing any of these parameters will cause the soil to absorb water and change its moisture perimeter.

This method is based on four main factors in calculating the soil moisture perimeter: dropper flow rate, irrigation duration, tillage depth, and soil bulk density. With this method, it is possible to determine the duration of intensive irrigation in certain soil conditions, which, in turn, contributes to an increase in the efficiency of water use.

\section{RESULTS OF RESEARCH}

A complete factorial experiment (CFE) is an experiment in which all possible repetitive combinations of $\mathrm{n}$ independently controlled factors are performed, each of which changes at two levels. In this case, the influence of the process under study on the response function takes into account their interaction, and not all factors taken into account in the experiment.
Based on the above (in the square $R e=R e_{g r}$ ), we can write:

$$
h / b=f\left(q, \rho, h_{K}, t\right)
$$

Where: $\mathbf{q}$ is the flow rate of dripping water, I/ $\mathrm{s} ; \boldsymbol{\rho}$ - soil density, $\mathrm{kg} / \mathrm{m}^{3} ; \mathbf{h}_{\mathbf{K}}$ - processing depth, $\mathrm{m} ; \mathbf{t}$ is the operating time of the dropper, hours.

In addition, methodological experiments make it possible to determine that the interdependence of these characteristics is not integral. The planning and implementation of a full-factor experiment is carried out with their responses, and not with specific characteristics, if necessary, taking into account the continuity of the model and bringing it into the desired form.

The design should select symmetrical experimental points relative to the zero level or centre of the experiment and separated from it by another intermediate value. The choice of the amount of change is determined by two conditions:

It must ensure that the factor level is not less than the detected error (otherwise the conditions do not differ) and that its maximum value ensures that all values obtained in the experiment fall within its definition. Proceeding from this, on the basis of preliminary experiments on a mathematical model, an interval of variation (interval) determined by the specific properties of soil moisture and the similarity of this phenomenon was obtained.

To get a linear model defined by the equation, it is enough to change two levels of factors - 
the maximum and minimum. In this case, experiments are defined by the following general formula:

$$
N=P K
$$

Where: $P$ is the number of levels of variability; $K$ is the number of factors involved in the experiment, so the number of factors studied as usual is $\mathrm{N}=2^{4}=16$. In this case, all possibilities of combining the level of factors are realized, which is a characteristic feature of this model. An experiment with a full coefficient (multiplier).

To simplify the recording of the experimental conditions and processing, the data on the factors were selected in such a way that the high level was $+1,-1$, and the base level corresponded to zero. For factors with a continuous region observed under our conditions, using these experiments, we can do the following:

$$
X_{J}=\frac{x_{J}-x_{J O}}{\Delta x_{J}}
$$

Where: J-serial number; $\mathrm{X}_{\mathrm{J}}$ - coded value of the

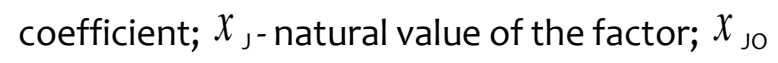
- natural value of the base level; $\Delta x_{\text {j }}$ - factor variation interval. The factors at all levels shown in Table 1 represent the design matrix, in which the rows correspond to the various experiments and the columns correspond to the factor values.

\begin{tabular}{|c|c|c|c|c|c|c|c|c|c|c|c|c|}
\hline \multirow{2}{*}{$\begin{array}{c}\text { Option } \\
\text { No. }\end{array}$} & \multicolumn{4}{|c|}{ Natural value } & \multicolumn{4}{|c|}{ Code value } & \multirow{3}{*}{$\begin{array}{c}\text { hour } \\
10\end{array}$} & \multirow{3}{*}{$\begin{array}{l}\text { b } \\
\\
11\end{array}$} & \multirow{2}{*}{\multicolumn{2}{|c|}{$\mathbf{Y}$}} \\
\hline & $\begin{array}{c}X_{4}= \\
q\end{array}$ & $\begin{array}{c}\mathrm{X}_{1}= \\
\mathrm{p}\end{array}$ & $\begin{array}{c}X_{2}= \\
h\end{array}$ & $\begin{array}{c}x_{3}= \\
t\end{array}$ & $X_{1}$ & $x_{2}$ & $x_{3}$ & $x_{4}$ & & & & \\
\hline 1 & 2 & 3 & 4 & 5 & 6 & 7 & 8 & 9 & & & 12 & 13 \\
\hline 1 & 8 & 1.52 & 0.3 & 20 & +1 & +1 & +1 & +1 & 1.13 & 1.22 & 28.9 & 25,7 \\
\hline 2 & 8 & 1.52 & 0.3 & 10 & +1 & +1 & +1 & -1 & 0.86 & 1.08 & 28.4 & 23.2 \\
\hline 3 & 8 & 1.52 & 0.15 & 20 & +1 & +1 & -1 & +1 & 1.10 & 1.21 & 22.3 & 20.6 \\
\hline 4 & 8 & 1.52 & 0.15 & 10 & +1 & +1 & -1 & -1 & 0.83 & 1.05 & 20.2 & 17.6 \\
\hline 5 & 8 & 1.22 & 0.3 & 20 & +1 & -1 & +1 & +1 & 1.27 & 0.76 & 34,7 & 31.2 \\
\hline 6 & 8 & 1.22 & 0.3 & 10 & +1 & -1 & +1 & -1 & 1.06 & 0.64 & 30.1 & 29.7 \\
\hline 7 & 8 & 1.22 & 0.15 & 20 & +1 & -1 & -1 & +1 & 1.12 & 0.77 & 29.7 & 26.8 \\
\hline
\end{tabular}

Table 1. Condition for carrying out a four-factor experiment. 


\begin{tabular}{|c|c|c|c|c|c|c|c|c|c|c|c|c|}
\hline 8 & 8 & 1.22 & 0.15 & 10 & +1 & -1 & -1 & -1 & 1.05 & 0.66 & 28.3 & 25,7 \\
\hline 9 & 2 & 1.52 & 0.3 & 20 & -1 & +1 & +1 & +1 & 1.05 & 0.98 & 28.7 & 26.4 \\
\hline 10 & 2 & 1.52 & 0.3 & 10 & -1 & +1 & +1 & -1 & 0.83 & 0.88 & 27.5 & 25.6 \\
\hline 11 & 2 & 1.52 & 0.15 & 20 & -1 & +1 & -1 & +1 & 0.98 & 0.96 & 26.2 & $25 \cdot 3$ \\
\hline 12 & 2 & 1.52 & 0.15 & 10 & -1 & +1 & -1 & -1 & 0.81 & 0.86 & 25,7 & 23.8 \\
\hline 13 & 2 & 1.22 & 0.3 & 20 & -1 & -1 & +1 & +1 & 1.13 & 0.77 & 29.4 & 26.1 \\
\hline 14 & 2 & 1.22 & 0.3 & 10 & -1 & -1 & +1 & -1 & 0.96 & 0.62 & 32.8 & 28.7 \\
\hline 15 & 2 & 1.22 & 0.15 & 20 & -1 & -1 & -1 & +1 & 1.09 & 0.71 & 28.1 & 25.3 \\
\hline 16 & 2 & 1.22 & 0.15 & 10 & -1 & -1 & -1 & -1 & 0.93 & 0.61 & 298 & 27.1 \\
\hline
\end{tabular}

Building an experimental design following the above scenarios will allow you to get a model with some functions that will later be used in calculations. This includes: symmetry property.

$$
\sum_{I=1}^{N} X_{J I}=0
$$

Here: J - factor number, I - experiment number; normalization mode:

$$
\sum_{I=1}^{N} X_{J I}^{2}=N
$$

Orthogonal attribute of the planning matrix:

$\sum_{I=1}^{N} X_{J I} X_{U I}=0$
When determining the soil moisture perimeter, a linear mathematical model was adopted, in which the natural logarithms of the initial soil absorption properties of water were taken as the previously determined coefficients $X_{1}, X_{2}$, $X_{3}, X_{4}$. The general form of expressions can be determined by the formulas:

$$
\begin{aligned}
& Y=B_{0}+B_{1} X_{1}+B_{2} X_{2}+B_{3} X_{3}+B_{4} X_{4}+B_{12} X_{1} X_{2}+B_{13} X_{1} X_{3}+B_{14} X_{1} X_{4}+B_{23} X_{2} X_{3}+ \\
& +B_{24} X_{2} X_{4}+B_{34} X_{3} X_{4}+B_{123} X_{1} X_{2} X_{3}+B_{124} X_{1} X_{2} X_{4}+ \\
& +B_{134} X_{1} X_{3} X_{4}+B_{234} X_{2} X_{3} X_{4}+B_{1234} X_{1} X_{2} X_{3} X_{4}
\end{aligned}
$$

To calculate the values of the $\mathbf{B} \boldsymbol{J}$ coefficients, a full factorial experiment was carried out, during which a combination of all factors was performed.

Where: $\mathrm{J} \neq \mathrm{U}, \mathrm{J}, \mathrm{U}=1,2,3, \ldots \mathrm{K}$. 
Table 2. Full planning factor for full factorial experience

\begin{tabular}{|c|c|c|c|c|c|c|c|c|c|c|c|c|c|c|c|c|}
\hline No. & $x$ & $\vec{x}$ & $x^{*}$ & $x^{m}$ & $x_{x}^{ \pm}$ & $\underset{x}{x}$ & $\underset{\underset{x}{x}}{\stackrel{m}{x}}$ & $\underset{\vec{x}}{\stackrel{ \pm}{x}}$ & 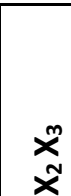 & $\underset{\underset{x}{x}}{\stackrel{x}{ \pm}}$ & $\begin{array}{l}x^{ \pm} \\
x^{ \pm}\end{array}$ & $\begin{array}{l}\underset{x}{x} \\
\vec{x} \\
\vec{x}\end{array}$ & 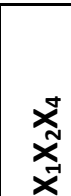 & $\begin{array}{l}x^{ \pm} \\
x_{x}^{m} \\
\dot{x}\end{array}$ & $\begin{array}{l}\dot{x} \\
x^{m} \\
\tilde{x}\end{array}$ & $\begin{array}{l}\vec{x} \\
x^{m} \\
\vec{x} \\
\vec{x}\end{array}$ \\
\hline 1 & 1 & 1 & 1 & 1 & 1 & 1 & 1 & 1 & 1 & 1 & 1 & 1 & 1 & 1 & 1 & 1 \\
\hline 2 & 1 & 1 & 1 & 1 & -1 & 1 & 1 & -1 & 1 & -1 & -1 & 1 & -1 & -1 & -1 & -1 \\
\hline 3 & 1 & 1 & 1 & -1 & 1 & 1 & -1 & 1 & -1 & 1 & -1 & -1 & 1 & -1 & -1 & -1 \\
\hline 4 & 1 & 1 & 1 & -1 & -1 & 1 & -1 & -1 & -1 & -1 & 1 & -1 & -1 & 1 & 1 & 1 \\
\hline 5 & 1 & 1 & -1 & 1 & 1 & -1 & 1 & 1 & -1 & -1 & 1 & -1 & -1 & 1 & -1 & -1 \\
\hline 6 & 1 & 1 & -1 & 1 & -1 & -1 & 1 & -1 & -1 & 1 & -1 & -1 & 1 & -1 & 1 & 1 \\
\hline 7 & 1 & 1 & -1 & -1 & 1 & -1 & -1 & 1 & 1 & -1 & -1 & 1 & -1 & -1 & 1 & 1 \\
\hline 8 & 1 & 1 & -1 & -1 & -1 & -1 & -1 & -1 & 1 & 1 & 1 & 1 & 1 & 1 & -1 & -1 \\
\hline 9 & 1 & -1 & 1 & 1 & 1 & -1 & -1 & -1 & 1 & 1 & 1 & -1 & -1 & -1 & 1 & -1 \\
\hline 10 & 1 & -1 & 1 & 1 & -1 & -1 & -1 & 1 & 1 & -1 & -1 & -1 & 1 & 1 & -1 & 1 \\
\hline 11 & 1 & -1 & 1 & -1 & 1 & -1 & 1 & -1 & -1 & 1 & -1 & 1 & \begin{tabular}{|l|}
-1 \\
\end{tabular} & 1 & -1 & 1 \\
\hline 12 & 1 & -1 & 1 & -1 & -1 & -1 & 1 & 1 & -1 & -1 & 1 & 1 & 1 & -1 & 1 & -1 \\
\hline 13 & 1 & -1 & -1 & 1 & 1 & 1 & -1 & -1 & -1 & -1 & 1 & 1 & 1 & -1 & -1 & 1 \\
\hline 14 & 1 & -1 & -1 & 1 & -1 & 1 & -1 & 1 & -1 & 1 & -1 & 1 & -1 & 1 & 1 & -1 \\
\hline 15 & 1 & -1 & -1 & -1 & 1 & 1 & 1 & -1 & 1 & -1 & -1 & -1 & 1 & 1 & 1 & -1 \\
\hline 16 & 1 & -1 & -1 & -1 & -1 & 1 & 1 & 1 & 1 & 1 & 1 & -1 & -1 & -1 & -1 & 1 \\
\hline
\end{tabular}

The experiment must ensure that the influence of the random parameters of the process under study on the response function is minimized. To minimize the impact of the experiment on the final results, the following requirements must be met:

- Conducting several parallel experiments under the same conditions provided in the corresponding row of the planning matrix (experiment number);

- It is necessary to classify the parameters of an uncontrolled process, i.e. ensure their mutual compensation.

To satisfy the first requirement, at least two parallel experiments must be carried out, and their number must be increased to ensure high reliability of the results. In our case, the repeatability of the experiments was $n=4$.

In this case, the results of $\mathrm{n}$ parallel experiments for each row of the planning matrix were averaged, and when analysing the experimental results, the response function and the average value corresponding to the experimental conditions were calculated using the following formula:

$\bar{Y}=\frac{\sum_{i=1}^{n} Y_{i}}{n}$

To minimize the influence of external variables, not included in the design, but affecting the experiment, the experimental design was evaluated in a random way, that is, the levels of 
the variables and the sequence of experiments were chosen at random in accordance with some unregulated rules. All these experiments made it possible to more or less distribute the influence of external factors on conditions.

Uncertainty of the response surface can also be related to the degree of influence of one factor on another. In this case, an interaction effect occurs. Table 3 shows the measured and average values of the logarithms of the resistance coefficient of the combined perimeter of the experiment:

$\mathrm{Y}=\ln \xi$.

The arithmetic mean variables in each row of the matrix are determined by the following formula:

$S_{I}^{2}=\frac{\sum_{I=1}^{m}\left[\overline{Y_{1}}-Y_{1}\right]^{2}}{m-1}$

Because even one big error can skew the test results, it is important to control the reproducibility of the test results. The homogeneity of variances is checked using the Cochrane test. Application of dependencies to (5) and (6) is limited to observance of experiments $\mathrm{S}_{1}{ }^{2}$ in case of homogeneity of differences in the exact factorial experiment.

$h=f\left(q, \rho, h_{k}, t\right)$ for the variant

$$
C=0.0071224 / 0.026618=0.268
$$

$b=f\left(q, \rho, h_{k}, t\right)$ for the variant

$$
G_{\max }=\frac{S_{I \max }^{2}}{\sum_{i=1}^{N} S_{I i}^{2}}=0.0052336 / 0.022722=0.230
$$

For a typical combined region, where the largest coefficient of change is the sum of the differences of all experiments with the critical Cochrane number as a function of the number of degrees of freedom ( $m=3$ and $k=16-1=15$ $\left.G_{K R}=0.373\right), G_{\text {MAX }}<G c n$. On the homogeneity of dispersions.

\section{CONCLUSIONS}

In conclusion, we can say that in a four-factor experiment, a change in any factor leads to a change in the dynamics of water absorption into the soil. Which, in turn, helps determine when to water in order to provide the right amount of water for the plant. In this way, the duration of crop irrigation is precisely determined and water loss is prevented.

\section{REFERENCES}

1. Dospekhov B.A. Methodology of field experience. Moscow. Agropromizdat, 1985.351 p. (In Russian)

2. Rahman, A. S. (2019). Effects of nanofibers on properties of geopolymer composites. In Nanotechnology in Eco-efficient Construction (pp. 123-140). Woodhead Publishing.

3. Sarimsakov, M. M., Abdisamatov, O. S., \& Umarova, Z. T. (2020). Influence of elements of irrigation equipment on irrigation erosion. Irrigation and Melioration, 2020(2), 7-10. 
4. Khamidov, F. R., Imomov, S. J., Abdisamatov, O. S., Sarimsaqov, M. M., Ibragimova, G. K., \& Kurbonova, K. I. (2020). Optimization of agricultural lands in land equipment projects. Journal of Critical Reviews, 7(11), 1021-1023

5. Das, A. K., \& Dewanjee, S. (2018). Optimization of extraction using mathematical models and computation. In Computational phytochemistry (pp. 75106). Elsevier.

6. Paul A. L., Michael F.G., David J. M., David W. R. Geographic Information Systems and Science.-UK 2nd edition "Zhokhn viley \& Sons Ltd., 2005. - 517 p.

7. Sahoo, P., \& Barman, T. K. (2012). ANN modelling of fractal dimension in machining. In Mechatronics and manufacturing engineering (pp. 159-226). Woodhead Publishing.

8. Klemes, J. J., Varbanov, P. S., \& Liew, P. Y. (2014). 24th European Symposium on Computer Aided Process Engineering: Part $A$ and B. Elsevier.

9. Evett, S., Ibragimov, N., Kamilov, B., Esanbekov, Y., Sarimsakov, M., Shadmanov, J., ... \& Muhammadiev, B. (2007). Neutron moisture meter calibration in six soils of Uzbekistan affected by carbonate accumulation. Vadose Zone Journal, 6(2), 406-412.

10. Sarimsakov, M. M., Umarova, Z. T., \& Otakhonov, M. Y. (2015). Cultivation and ways of watering varieties of fruit trees. Journal of Irrigation and Land Reclamation, (2-P), 9.
11. Yizhar, O., Fenno, L. E., Prigge, M., Schneider, F., Davidson, T. J., O'shea, D. J., ... \& Deisseroth, K. (2011). Neocortical excitation/inhibition balance in information processing and social dysfunction. Nature, 477(7363), 171-178.

12. Mangun, G. R., \& Hillyard, S. A. (1991). Modulations of sensory-evoked brain potentials indicate changes in perceptual processing during visual-spatial priming. Journal of Experimental Psychology: Human perception and performance, 17(4), 1057.

13. Ren, C., Zhao, Y., Dan, B., Wang, J., Gong, J., \& He, G. (2018). Lateral hydraulic performance of subsurface drip irrigation based on spatial variability of soil: experiment. Agricultural Water Management, 204, 118-125.

14. Mamataliev, A. B. Drip irrigation () F () II, crops.

15. Wang, P., Hu, Z., Zhao, Y., \& Li, X. (2016). Experimental study of soil compaction effects on GPR signals. Journal of Applied Geophysics, 126, 128-137.

16. Musinovich, Sarimsakov Maksudkhon, Kimsanov Ibrahim Khaitmuratovich, and Umarova Zulaykho Tulkunovna. "Application of Water-Saving Technologies In Gardening Uzbekistan." The American Journal of Agriculture and Biomedical Engineering 3.08 (2021): 1-8.

17. Hamann, F. A., Czaja, S., Hunsche, M., Noga, G., \& Fiebig, A. (2018). Monitoring physiological and biochemical responses of two apple cultivars to water supply 
The American Journal of Interdisciplinary Innovations and Research (ISSN-2642-7478)

Published: November 12, 2021 | Pages: 1-8

Doi: https://doi.org/10.37547/tajiir/Volume03Issue11-01

regimes with non-destructive

fluorescence sensors. Scientia

Horticulturae, 242, 51-61. 